\title{
Adverse events in cancer patients with sickle cell trait or disease: case reports
}

\author{
Helen Swede, PhD', Biree Andemariam, MD², David I. Gregorio, PhD ${ }^{1}$, Beth A. Jones, PhD, MPH${ }^{3}$, \\ Dejana Braithwaite, $\mathrm{PhD}^{4}$, Thomas E. Rohan, MD, PhD ${ }^{5}$ and Richard G. Stevens, $\mathrm{PhD}^{1}$
}

\begin{abstract}
Purpose: Given the relatively high prevalence of sickle cell trait and disease among African Americans and established racial disparities in cancer outcomes, we reviewed the literature regarding adverse events in cancer patients with these hematologic genotypes. Erythrocyte sickling can result from extreme hypoxia and other physiologic stressors, as might occur during cancer therapy. Further, tumoral hypoxia, a poor prognostic and predictive factor, could lead to a cycle of local sickling and increased hypoxia.
\end{abstract}

Methods: A search of PubMed produced 150 publications, most of which were excluded because of incidental relevance. Eleven case reports of patients diagnosed from 1993 to 2013 were reviewed.

Results: Two reports of patients with sickle cell trait describe an abundance of sickled erythrocytes within tumors, and a third report describes sickling-related events requiring multiday hospi- talization. Eight reports of patients with sickle cell disease delineated multiorgan failure, vaso-occlusive crises, and rapid renal deterioration. Hypothesized triggers are delayed clearance of anticancer agents attributable to baseline kidney damage, activation of vasoadherent neutrophils from treatment to counter chemotherapy-induced neutropenia, hypoxia from general anesthesia, and intratumoral hypoxia.

Conclusion: Clinical implications include pretreatment genotyping for prophylaxis, dose adjustment, and enhanced patient monitoring. With the current lack of high-quality evidence, however, the scope of poor outcomes remains unknown.

Genet Med advance online publication 21 August 2014

Key Words: cancer; cancer adverse effects; disparities; hypoxia; sickle cell disease; sickle cell trait

\section{INTRODUCTION}

African Americans have the highest mortality rates of all race/ ethnic groups in the United States for all cancers combined, ${ }^{1}$ most notably for breast, prostate, colorectal, lung, and uterine cervix. Although socioeconomic influences and access to care have been linked to outcome disparities in many studies, others report persistence of poor results despite accounting for these factors. ${ }^{2}$ The impact of sickle cell trait (SCT) or sickle cell disease (SCD) - genotypes substantially more prevalent in African Americans-is unknown. Approximately 8.3\% (2.5 million) of African Americans are estimated to be SCT carriers compared with $0.05 \%$ of whites, ${ }^{3}$ which prompts the question of whether sickling-related adverse events during the physiologic rigors of systemic cancer therapy might explain, in part, disparities in outcomes.

SCD is caused by an inherited point mutation in both alleles of the $\beta$-globin gene, whereas in SCT only one allele houses the constitutional mutation. ${ }^{3}$ Sickling refers to the transformation of erythrocytes into an abnormal sickled shape, typically under conditions of low oxygenation (e.g., high altitude, dehydration). Sickled cells can cluster and adhere to walls of blood vessels, thereby severely blocking blood flow and resulting in extreme pain and tissue damage. Manifestations also may be related to inflammation of blood vessels and impaired vascular function. For SCT, however, conventional wisdom has held that frank sickling is rare but is known to occur under certain physiological challenges such as extreme hypoxia and other stressors. ${ }^{4} \mathrm{~A}$ recent review, however, reports emerging data about various health complications associated with SCT such as renal deterioration, hematuria, renal medullary carcinoma, and exercise-related sudden death, and calls for a national research agenda to determine triggers of sicklingrelated events in SCT. ${ }^{4}$ Although the underlying pathology in the development of these complications in SCT remains virtually unknown, a recent in vitro study by Maciaszek et al. ${ }^{5}$ of blood cell reactivity in SCT patients observed increased frequency and strength of adhesion events in red blood cells (RBCs) on exposure to epinephrine, a hormone secreted during the sympathetic stress response.

Here, we review the literature on adverse events among cancer patients in the SCT and SCD genetic population. This review is limited to case reports because we found no publications from analytical studies. This is the first compilation, to our knowledge, of this descriptive evidence in a single venue.

${ }^{1}$ Department of Community Medicine, University of Connecticut School of Medicine, Farmington, Connecticut, USA; ${ }^{2}$ Lea's Foundation Center for Hematologic Disorders, Division of Hematology/Oncology, Connecticut School of Medicine, Farmington, Connecticut, USA; ${ }^{3}$ Department of Chronic Disease Epidemiology, Yale School of Public Health, New Haven, Connecticut, USA; ${ }^{4}$ Department of Epidemiology and Biostatistics, University of California, San Francisco, San Francisco, California, USA; ${ }^{5}$ Department of Epidemiology and Population Health, Albert Einstein College of Medicine, Bronx, New York, USA. Correspondence: Helen Swede(hswede@uchc.edu) 
With an estimated 300 million SCT carriers worldwide, ${ }^{4}$ identification of sickling triggers and related complications offers an opportunity to improve quality of care and survival for a vast number of cancer patients.

\section{MATERIALS AND METHODS}

A search of the PubMed.gov database (US National Library of Medicine) using broad MeSH terms returned 150 articles for screening (Figure 1). Of these, 11 case reports were selected for review; one article described two persons, for a total of 12 patients diagnosed from 1999 to 2013 (Table 1). Studies that reported adverse effects related to systemic cancer therapy and putatively attributed to SCT or SCD were included in the review. No analytic studies or review articles were found. Reasons for excluding studies during the screening step were as follows: lack of information on cancer treatment; SCT or SCD found to be incidental to the investigation; analysis of cancer as an outcome among the SCT or SCD populations; commentaries; and unrelated to SCT/SCD or cancer. We did not restrict our search to a certain time period or study type. We also abstracted proposed hypotheses about biologic mechanisms of sickling in cancer patients.

\section{Sickle cell trait}

\section{RESULTS}

In a case report of an SCT patient with cervical cancer (Table 1), Milosevic et al. ${ }^{6}$ observed extensive erythrocyte sickling within the small vessels of the pretreatment biopsy specimen. Also present were RBCs with abnormal morphology indicative of intermediate phases of sickling. In a second SCT patient, Agrawal et al. ${ }^{7}$ also reported abundant sickling in the tumor specimen. The patient was diagnosed with a low-grade glioma and developed left-sided hemiplegia with severely altered sensorium. A third report of a 54-year-old breast cancer patient described shortness of breath, severe chest pain, and diffuse body aches during cycle 4 of chemotherapy after addition of granulocyte colony-stimulating factor (G-CSF) during cycle 1 to treat and prevent neutropenic fever. ${ }^{8}$

\section{Sickle cell disease}

Eight case reports of nine patients described adverse events during systemic cancer therapy. Six patients harbored the classical genotype, $, 10,12,13,17$ and three were found to have compound sickle beta thalassemia, ${ }^{11,14,15}$ a clinically milder form of SCD. ${ }^{16}$ Complications included vaso-occlusive crisis, ${ }^{10,15}$ multiorgan failure, ${ }^{11}$ deteriorating renal function, ${ }^{14,17}$ thrombocytopenic purpura/hemolytic uremic-like syndrome, ${ }^{14} 6$ months of persistently elevated hemoglobin $\mathrm{F}^{13}$ pulmonary embolism, ${ }^{12}$ and severe lower back pain., ${ }^{9,11,15}$ Three patients required multiple weeks of hospitalization..$^{9,11,17}$

\section{DISCUSSION}

Evidence from this limited number of case reports suggests provocation of sickling or related complications among persons with SCT or SCD genotypes in the face of physiologic rigors of treatment and biologic conditions favoring hypoxia in the intratumoral environment. Although underlying biologic mechanisms are not understood, ${ }^{8,9,14}$ several authors of case reports put forth hypotheses. Intratumoral deformation of erythrocytes was attributed to hypoxic conditions detected in the microvasculature in the two reports of SCT patients. ${ }^{67}$ Milosevic et al. ${ }^{6}$ hypothesized that focal areas of hypoxia in the tumor coupled with long transit times in the abnormal structures of the microcirculation would be sufficient to trigger sickling of vulnerable erythrocytes in SCT carriers, although it is possible that sickling in tumors might have been attributable to ex vivo conditions. High or low temperatures and prolonged drying time of tissue are two such factors that might produce false-positive changes in RBC morphology. ${ }^{18}$ Brown et al., ${ }^{19}$ however, reported in vivo evidence that sickled RBCs preferentially aggregated in the vasculature of rat gliomas relative to normal brain tissue based on magnetic resonance imaging scans of radiation-labeled RBCs.

Neurological complications in the glioma patient with SCT were attributed to severe necrosis of the tumor resulting from a cycle of hypoxia, sickling, thrombosis, ischemia, and infarction. ${ }^{7}$ This cycle was hypothesized to stem from initial sickling from intratumoral hypoxia, followed by amplification of hypoxia as a result of the propensity of sickled cells to adhere to

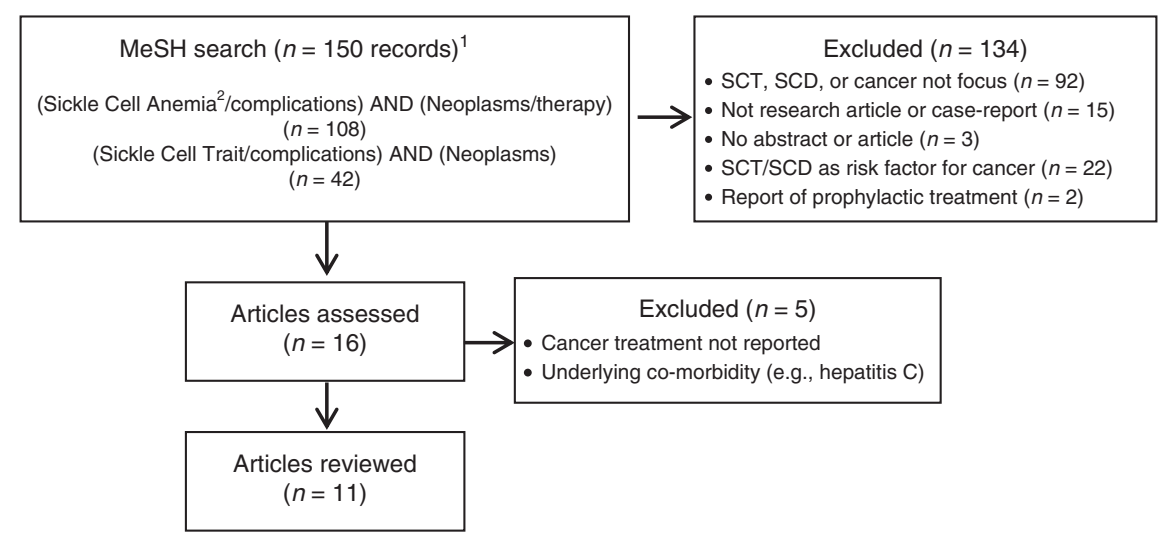

Figure 1 Flowchart of articles selected for review. ${ }^{1}$ Filters: Humans; English; NOT renal medullary carcinoma. ${ }^{2}$ Sickle beta thalassemia also assigned to this MeSH term. 
Table 1 Summary of case reports of sickling-related events among cancer patients with sickle cell trait or disease

\begin{tabular}{|c|c|c|c|c|c|c|}
\hline & Genotype & Site & Age, sex & Systemic agent(s) & Complications & Resolution \\
\hline $\begin{array}{l}\text { Kasi et al. } \\
(2013)^{8}\end{array}$ & $\mathrm{SCT}$ & Breast & 54 years, female & $\begin{array}{l}\text { Docetaxel, } \\
\text { cyclophosphamide with } \\
\text { G-CSF added to regimen } \\
\text { for neutropenia }\end{array}$ & $\begin{array}{l}\text { Cycle 1: Neutropenic fever requiring } \\
\text { hospitalization; G-CSF added } \\
\text { Cycle } 4 \text { : Shortness of breath, severe } \\
\text { chest pain, and diffuse body aches } \\
\text { requiring hospitalization }\end{array}$ & $\begin{array}{l}\text { Responded well } \\
\text { to intravenous } \\
\text { hydration and pain } \\
\text { control }\end{array}$ \\
\hline $\begin{array}{l}\text { Milosevic } \\
\text { et al. }(2001)^{6}\end{array}$ & $\mathrm{SCT}$ & $\begin{array}{l}\text { Uterine cervix } \\
\text { stage IIIB }\end{array}$ & 63 years, female & - & $\begin{array}{l}\text { Extensive sickling in } \\
\text { microvasculature of untreated } \\
\text { biopsied tumor specimen }\end{array}$ & N/A \\
\hline $\begin{array}{l}\text { Shrestha } \\
\text { et al. } \\
(2011)^{14}\end{array}$ & $\mathrm{SCT} / \beta+$ & $\begin{array}{l}\text { Prostate stage } \\
\text { IV }\end{array}$ & 63 years, male & Docetaxel & $\begin{array}{l}\text { Cycle 1, day 2: TIP/HUS-like, } \\
\text { deteriorating renal function, } \\
\text { hemolysis }\end{array}$ & $\begin{array}{l}\text { Prednisone, } \\
\text { transfusion; } \\
\text { hemodialysis; 18+ } \\
\text { day hospitalization }\end{array}$ \\
\hline $\begin{array}{l}\text { Grigg } \\
(2001)^{11}\end{array}$ & $\mathrm{SCT} / \beta+$ & Breast stage II & 58 years, female & CMF followed by G-CSF & $\begin{array}{l}\text { Cycle 2, day 9: Treated with G-CSF } \\
\text { for neutropenia; multiorgan failure } \\
\text { with severe lower back pain, } \\
\text { respiratory distress, severe hypoxia, } \\
\text { dyspnea, mechanical ventilation }\end{array}$ & $\begin{array}{l}\text { Transfusion for } \\
6 \text { weeks; organ } \\
\text { failure resolved after } \\
2 \text { weeks; 8-week } \\
\text { hospital stay }\end{array}$ \\
\hline $\begin{array}{l}\text { Savaşan } \\
\text { and Sarnaik } \\
(2012)^{13}\end{array}$ & SCD & $\begin{array}{l}\text { Wilm's tumor } \\
\text { unknown stage }\end{array}$ & 8 years, female & $\begin{array}{l}\text { Vincristine, doxorubicin, } \\
\text { actinomycin } D \text {; radiation }\end{array}$ & $\begin{array}{l}\text { No complications during primary } \\
\text { therapy; persistent elevated fetal } \\
\text { hemoglobin for } 6 \text { years }\end{array}$ & \\
\hline $\begin{array}{l}\text { Brown } \\
\text { and Kotila } \\
(2007)^{10}\end{array}$ & $S C D$ & $\begin{array}{l}\text { Hodgkins } \\
\text { lymphoma }\end{array}$ & 7 years, male & COPP & $\begin{array}{l}\text { Cycles 3, 4: Three vaso-occlusive } \\
\text { crises }\end{array}$ & $\begin{array}{l}\text { Episodes resolved } \\
\text { within } 3 \text { days }\end{array}$ \\
\hline $\begin{array}{l}\text { Mantadakis } \\
\text { et al. } \\
(1999)^{17}\end{array}$ & SCD & Osteosarcoma & 15 years, female & $\begin{array}{l}\text { Cisplatin-doxorubicin, } \\
\text { etoposide- } \\
\text { cyclophosphamide, and } \\
\text { high-dose methotrexate }\end{array}$ & $\begin{array}{l}\text { Delayed clearance of chemotherapy } \\
\text { after second course resulted in } \\
\text { renal and hepatic toxicities; } 12 \text {-day } \\
\text { hospitalization }\end{array}$ & $\begin{array}{l}\text { Resolved with high- } \\
\text { dose leucovorin, } \\
\text { carboxypeptidase G2, } \\
\text { and thymidine; focal } \\
\text { tonic-clonic seizures } \\
\text { developed but } \\
\text { resolved after } \\
4 \text { weeks }\end{array}$ \\
\hline
\end{tabular}

COPP, cyclophosphamide, vincristine, procarbazine, prednisone; CMF, cyclophosphamide, methotrexate, fluorouracil; G-CSF, granulocyte colony-stimulating factor; SCD, sickle cell disease; SCT, sickle cell trait; SCT/B+, sickle beta thalassemia (i.e., joint SCT and beta thalassemia carriers); TIP/HUS, thrombocytopenic purpura/hemolytic uremic syndrome.

the vascular endothelium and, thereby, to occlude the lumen. ${ }^{6,7}$ Pretherapeutic hypoxia in solid tumors is considered a prognostic factor for disease progression and resistance to systemic therapy. ${ }^{20}$ Chronic hypoxia and acidosis in the kidneys of persons with SCT and SCD is thought to provide fertile ground for RBC sickling, which also has been suspected in the pathogenesis of renal medullary carcinoma, ${ }^{21}$ an aggressive malignancy almost exclusively associated with these genotypes. 
In case reports of patients with $\mathrm{SCT}^{8}$ and $\mathrm{SCD},{ }^{11}$ administration of G-CSF was thought to prompt systemic sickling attributable to enhanced neutrophil number, activation, and endothelial attachment-processes known to enhance vasoocclusion by sickled cells. Included in the SCT case report by Kasi et al. ${ }^{8}$ is a summary of adverse events attributed to G-CSF observed in SCT patients in other settings such as treatment for sickle-related ulcers. The authors of two case reports speculated that drug-specific adverse pharmacological effects in SCT/SCD patients might develop only above a threshold dose. ${ }^{11,12}$ However, Mantadakis et al. ${ }^{17}$ suggest it might be prudent to completely avoid administration of intensive anticancer chemotherapeutic agents with known nephrotoxicities to SCD patients, given existing multiorgan damage frequently seen in this population. Specifically, they attributed the rapid deterioration of renal function to the effects of delayed clearance of renally excreted methotrexate, a delay suspected to be caused by underlying kidney damage. Other proposed systemic triggers of sickling were the apoptotic cascade of erythrocytes during administration of paclitaxel and docetaxel ${ }^{9}$ and surgery and anesthesia, which might create hypoperfusion, hypoxia, or acidosis, ${ }^{12}$ known triggers of sickling. Finally, a pulmonary embolism experienced by one SCD patient was suspected to be related to the 6-month course of adjuvant tamoxifen treatment based on reports of the hypercoagulable milieu in SCD and risk of thromboembolism linked to tamoxifen. ${ }^{12}$

The relatively high prevalence of these genotypes in persons with African ancestry, particularly for SCT, compels the question: why might sickling-related events in cancer patients have gone virtually unnoticed? One explanation, at least for SCD, is the rarity of cancer in this population because of shorter life expectancy until recent decades. ${ }^{3,9}$ We also speculate that treatment-related difficulties in SCT might manifest more subtly than a severe crisis given the balancing presence of stable hemoglobin and the lower likelihood of underlying organ damage. Further, and probably most importantly, most adults with SCT are unaware of their carrier status even in the era of genomic medicine. ${ }^{3}$ Consequently, care providers likely would be unaware and subsequently might not associate nonspecific symptoms such as joint discomfort or declines in kidney function with a cause other than rigors of therapy. Lack of awareness of the range and impact of sickling-related events also might be a consequence of underrepresentation of minorities in clinical trials, ${ }^{22}$ which has resulted in limited evidence about differing responses to cancer therapy by race and ethnicity. ${ }^{1}$ Alternatively, it must be emphasized that the scarcity of evidence about serious complications simply might reflect a not unusual rate of adverse events among SCT or SCD patients with cancer.

A suggested next step could be in vitro assessments of blood reactivity to chemotherapeutic agents among $\mathrm{SCT}, \mathrm{SCD}$, and control groups along the lines of Maciaszek et al., ${ }^{5}$ who reported increased adhesive events in RBCs from SCT patients on stimulation by epinephrine. Such data could lay the biologic foundation for hypothesis-driven population-based outcomes research using appropriate control groups (e.g., whites and African Americans without SCT or SCD; cancer patients with other inherited hemoglobinopathies) to compare the frequencies and types of adverse events occurring during systemic anticancer treatment.

Existing databases from large, cooperative oncology trials with archival specimens offer opportunities to identify SCT and SCD genotypes and test hypotheses. A recent report of two Southwest Oncology Group clinical trials of various breast cancer treatment regimens indicated that African-American patients were more likely to discontinue adjuvant cytotoxic therapy. ${ }^{23}$ Did sickling-related complications underlie some of the withdrawals? Did discontinuation rates vary by systemic agent? Is there evidence of sickled RBCs in tumors, and is this linked with reduced efficacy of treatment, discontinuation of therapy, or poorer survival? Subpopulations of SCT and SCD patients could be assessed, such as those with underlying kidney dysfunction or genetic polymorphisms predisposing to slower clearance of antineoplastic agents. Similarly, ongoing prospective studies focused on multifactorial causation of early discontinuation in adjuvant cancer therapy could provide large-scale avenues for quantification of adverse events in SCT or SCD patients. SEER-Medicare claims data, electronic hospital records, and other statistical data sets also could provide avenues for analyses. A likely limitation, however, is an anticipated high degree of missing data, given that the vast majority of care providers are unaware of the SCT genotype status of their patients. Existing clinical or research data sets accompanied by tissue and serum archives, however, might offer more fruitful strategies because of the ability to perform genotyping assays.

Regarding the public health burden, adverse events related to gene-environment interactions in SCT or SCD patients in relation to certain systemic therapies and/or the general stressors of cancer treatment may be substantial in number. The American Cancer Society estimates that a total of 176,620 cancers cases were expected to be newly diagnosed in African Americans in 2013, and 64,880 deaths were projected to occur. ${ }^{1}$ Continued improvements in life expectancy in SCD will result in higher rates of malignancy. With hundreds of millions of SCT carriers worldwide, the possibility of subclinical sickling during systemic cancer treatment warrants future analytic investigations. Given that the majority of SCT carriers are unaware of their genetic status, ${ }^{3,4}$ translational implications might include genotyping among patients with newly diagnosed cancer for optimal agent selection, dose adjustment, and differential diagnoses of nonspecific events (e.g., renal decline, joint discomfort). With the current void of high-quality evidence, however, the magnitude and scope of poor outcomes are not known, nor are optimal clinical strategies for cancer patients with SCT or SCD genotypes.

\section{ACKNOWLEDGMENT}

This study was funded, in part, by the Connecticut Breast Health Initiative (501 (c)(3)). 


\section{DISCLOSURE}

The authors declare no conflict of interest.

\section{REFERENCES}

1. ACS. Cancer Facts \& Figures for African Americans, 2013-14. American Cancer Society, 2013.http://www.cancer.org/acs/groups/content/@ epidemiologysurveilance/documents/document/acspc-036921.pdf.

2. Du XL, Lin CC, Johnson NJ, Altekruse S. Effects of individual-level socioeconomic factors on racial disparities in cancer treatment and survival: findings from the National Longitudinal Mortality Study, 1979-2003. Cancer 2011;117:32423251 .

3. Taylor C, Kavanagh P, Zuckerman B. Sickle cell trait-neglected opportunities in the era of genomic medicine. JAMA 2014;311:1495-1496

4. Goldsmith JC, Bonham VL, Joiner CH, Kato GJ, Noonan AS, Steinberg MH. Framing the research agenda for sickle cell trait: building on the current understanding of clinical events and their potential implications. Am J Hematol 2012;87:340-346.

5. Maciaszek JL, Andemariam B, Huber G, Lykotrafitis G. Epinephrine modulates $\mathrm{BCAM} / \mathrm{Lu}$ and ICAM-4 expression on the sickle cell trait red blood cel membrane. Biophys J 2012;102:1137-1143.

6. Milosevic M, Quirt I, Levin W, Fyles A, Manchul L, Chapman W. Intratumora sickling in a patient with cervix cancer and sickle trait: effect on blood flow and oxygenation. Gynecol Oncol 2001;83:428-431.

7. Agrawal A, Balpande DN, Khan A, Vagh SJ, Shukla S, Chopra S. Sickle cell crisis leading to extensive necrosis in a low-grade glioma and masquerading highgrade lesion. Pediatr Neurosurg 2008:44:471-473.

8. Kasi PM, Patnaik MM, Peethambaram PP. Safety of pegfilgrastim (neulasta) in patients with sickle cell trait/anemia. Case Rep Hematol 2013;2013:146938.

9. Wilson NM, Espirito JL, Valero V, Pusztai L. Paclitaxel-induced sickle cell crisis. Am J Health Syst Pharm 2008;65:1333-1336.

10. Brown BJ, Kotila TR. Hodgkin lymphoma in a child with sickle cell anemia Pediatr Hematol Oncol 2007;24:531-535.
11. Grigg AP. Granulocyte colony-stimulating factor-induced sickle cell crisis and multiorgan dysfunction in a patient with compound heterozygous sickle cell/ beta+ thalassemia. Blood 2001;97:3998-3999

12. Gupta E, Guthrie T. Breast cancer in sickle cell disease. Breast J 2012;18:647649.

13. Savaşan S, Sarnaik SA. Persistent elevation of fetal hemoglobin following chemotherapy in sickle cell disease. Pediatr Blood Cancer 2012;59:199200.

14. Shrestha A, Khosla P, Wei Y. Docetaxel-induced thrombotic thrombocytopenic purpura/hemolytic uremic syndrome-related complex in a patient with metastatic prostate cancer? Am J Ther 2011;18:e167-e171.

15. Lee $C$, Saunders $M$. Sickle cell crisis in a patient receiving capecitabine chemotherapy. Clin Oncol (R Coll Radiol) 2010;22:85-86

16. Platt OS, Thorington BD, Brambilla DJ, et al. Pain in sickle cell disease. Rates and risk factors. N Engl J Med 1991;325:11-16.

17. Mantadakis E, Rogers ZR, Smith AK, Quigley R, Ratliff AF, Kamen BA. Delayed methotrexate clearance in a patient with sickle cell anemia and osteosarcoma. $J$ Pediatr Hematol Oncol 1999;21:165-169.

18. Wilson Cl, Hopkins PL, Cabello-Inchausti B, Melnick SJ, Robinson MJ. The peripheral blood smear in patients with sickle cell trait: a morphologic observation. Lab Medicine 2000;31(8):445-447.

19. Brown SL, Ewing JR, Nagaraja TN, et al. Sickle red blood cells accumulate in tumor. Magn Reson Med 2003;50:1209-1214.

20. Vaupel $P$, Mayer A. Hypoxia in cancer: significance and impact on clinical outcome. Cancer Metastasis Rev 2007;26:225-239.

21. Figenshau RS, Basler JW, Ritter JH, Siegel CL, Simon JA, Dierks SM. Renal medullary carcinoma. J Urol 1998;159:711-713.

22. Kwiatkowski K, Coe K, Bailar JC, Swanson GM. Inclusion of minorities and women in cancer clinical trials, a decade later: have we improved? Cancer 2013;119:2956-2963.

23. Hershman DL, Unger JM, Barlow WE, et al. Treatment quality and outcomes of African American versus white breast cancer patients: retrospective analysis of Southwest Oncology studies S8814/S8897. J Clin Oncol 2009;27: 2157-2162. 